\title{
Two new interpretation of Plato's Protagoras
}

\author{
Sana Javanmardi*, Saeed Binaaye Motlaq \\ Department of Philosophy, Faculty of Literature and Human Scinces, University of Isfahan, \\ Isfahan, Iran \\ *E-mail address: sana_javanmardi@yahoo.com
}

\begin{abstract}
As we know, one of the most important ideas of Protagoras is Epistemic Relativism that this theory is attributed to him during the history of philosophy, without any dispute; But in the new era commentators such as Dr. Qavam Safari and Cornford by further and more precise reading the conversations between Protagoras and Theaetetus have concluded to this belief that Plato has interpreted the Protagoras' rule of "Humanism", by assimilating it with a course which he calls it "secret" and also the theory of Theaetetus "knowledge = perceiving", in a way that it leads to perfect and very sophisticated relativism; and then in an ahistorical effort, Plato has imposed this relativism to the Protagoras' mind. Whether this claim is proved or remained only as a claim, it should be discussed; so we have attempted to address this important issue in the present article.
\end{abstract}

Keywords: Sophist; Plato; Protagoras; Humanism; Relativism

\section{INTRODUCTION}

Before entering the main argument, firstly it is necessary to get briefly familiar with personal life and important ideas of Protagoras, the great sophist of the history of philosophy.

\section{Protagoras}

About his personal life, there are some contents sporadically in historical books; including that he is born in Abdera, a Lonian Colony, located on Thrace, at about 480 BC. in Ancient Greece; And Xerxes, the Persian king, for hospitality of Protagoras' father, ordered to teach literacy to him. Perhaps his first visit to Athens might have been before $433 \mathrm{BC}$. that he was invited from Pericles to write the new constitution of recently established PanHellenic city, "Thurii", in Southern Italy. He was about forty years in the Greek cities to educate youth, and was the first who took the training wage, and in later life due to writing a book about rejection of the gods, was sentenced to death in Athens, and all his books were burned in the public square, but he fled, and in the way of Sicily was killed in the Black Sea about 411 BC. (Kerferd. G.B, 1997, 229)

Protagoras was the most famous Sophists. Apparently, Plato declared him as the first person, who called himself Sophist and also received tuition for his training (a349Prot,). In fact, he could be named as the first and greatest Sophist that the human being and his life is his main concern. He not only did not limit his teaches domain to a particular topic, but also 
he was an expert in the art of rhetoric and the techniques it relies on, and also in some important issues such as education, law, ethics and politics (Gomperz, 1997, vol 1, 457).

Very few fragments from Protagoras have survived, though he is known to have written two major works: Antilogiae and Truth. The latter is cited by Plato, and was known

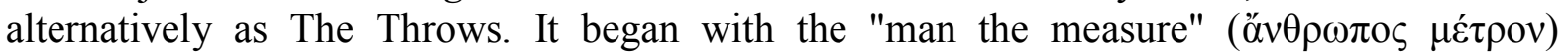
pronouncement. The first, "Antilogiae" which perhaps has been about Gods. It seems that the fundamental basis of charge of impiety to him is located in this work (On the Gods), the book that started with these words: "Concerning the gods, I have no means of knowing whether they exist or not or of what sort they may be, because of the obscurity of the subject, and the brevity of human life." (Kerferd, 1997, 229).

Probably the value of ritual religious, the subject of this book, has been as a part of civilized life, or perhaps it has described different forms of beliefs and worships anthropologically, common among the various ethnic groups. The book called "Great Logos" has also been mentioned, that might have been "Truth", which also there are other several titles (Guthrie, 1997, vol 11, 191).

Protagoras begins his book "Truth" with these words:

"Man is the measure of all things: of things which are, that they are, and of things which are not, that they are not".

This sentence became the basis of Protagoras' main philosophical thesis that causes friction and reaction of many others and it was because of his humanistic point of view. His intellectual and epistemological approach has become a foundation that he offered his philosophical insights on the basis of its centrality.

\section{SOME IMPORTANT PHILOSOPHICAL IDEAS OF PROTAGORAS}

\section{1. Individualism}

We could pursue the conversations of Socrates in Dialogue by Theaetetus to understand that the word "man" in Protagoras' sentence (man is the measure of all things) is an individual word or a practical one. Because Plato, as the first and oldest philosopher who discussed about Protagoras' opinions, had supposedly said of Socrates' talking to Theaetetus in this dialogue that:

"Those individual things are for me such as they appear to me and for you in turn such as they appear to you - you and I being "man"." (Theaetetus, 152)

Among these and many similar statements in the Epistle of Theaetetus, it certainly suggests that the Protagoras meant "a man". So we would be led to a kind of individualism. (Copleston, 1990, Vol 106, 1).

On the other hand, Protagoras believes that: No one can say contradictory to another's saying or consider his saying as a wrong expression; because the only judge of human's feelings and beliefs is human himself, and till he regards these as true affairs, these are true for him; because he believes that anyone who makes a percept, it's just according to what he has understood, so it's truth; because the truth is not apart from what the man understands and as individuals perceive differently, so one person thinks it's right while the other thinks it's wrong and the third person suspect what is right or wrong; therefore it is true and false, 
right and wrong together (Motahari, 1994, Vol 1, 57). Because the nature affects everyone in his judgments (Below, 1997, 81).

On the basis of what was mentioned, the criterion of right and wrong, truth and untruth is mankind, not the kind of man. Because some interpretations such as: the criterion of understanding is revealing a thing to man; and no one can bring contradictory to another's saying; and the uppermost is that a thing could be true and false together, could not be applicable for mankind. Therefore Protagoras considers mankind as the basis of everything including good and evil, presence and absence, quality and quantity, and thought and action; indeed the most prominent intellectual and epistemological basis of his is individualism and his emotion-oriented approach is also based on individualism.

\section{2. Sensationalism}

The most important debate that is about Protagoras' famous expression, and is also proposed in Socratic interpretations and criticisms, is the theory of sensory perception contained in it. The basis of this theory is whether the intent of Protagoras by "thing" in his famous sentence, "man is the measure of all things...", was only objects of sense or not.

Protagoras considers feeling and consequently senses as the only way of knowing and connection with the universe. He believes that the man has nothing just his senses to perceive affairs; because the reasoning is also based on sensory degrees, and sensory perception is different among individuals; so having no choice but to take authentic whoever feels whatever; while man knows that everyone perceives everything in his own way and those affairs which are feel, are not fixed and immutable, but rather unstable and convertible. (Foroughi, 1994, 16)

Some even likened him to John Locke and said:

Protagoras considered the feeling as the only means of awareness and knowledge and never believed in truth beyond the feeling, and said that there is no absolute truth, but it is whatever that occurs for certain people in certain circumstances (Will Durante, 1992,vol 2, 400). He even believed to gain geometry definitions from the tangible world which have no reasonable and former principles and also no perfect truth by their own nature (Gompertz, 1994, vol 1, 472).

As all the human feelings have rooted in different causes, in Protagoras point of view, are of equal value and rating. Nothing is superior to the other. In fact he considers the cause of equality of all people's feelings in the way that: in usual situation, a person perceives objects in a different way from in unusual situation. Thus the way of feeling is various according to age, sleep and waking, health and disease, and dementia. So how we can rate the feelings? Could we consider some as honest and true, but the others as false and virtual? Or as all feelings are natural, so their causes are out of hands and all of them are true; so everything is true (Mahdavi, 1995, 27). Protagoras believes that wholesome feeling and temperament is related to lucid ideas and sagacity, because he just calls one as a wise who has the most common temperament. This person has the most common, powerful and perfect ideas (Guthrie, 1994, vol 2, 20).

Finally as we, human beings, are with different feeling and wisdom, so all objects proportionally are different, thus all perceptions are true and real (Takrini, 1979, 15). So according to what we described, it becomes clear that as he believes in the theory of sensory perception, therefore his purpose by "things" is sensory phenomena which are understandable by feelings. 


\section{3. Relativism}

Protagoras' claims in the fields, individualism and sentimentalism led to cognitive relativism. If there have been no fixed and objective substance, in other words, a constant affair in objects, then in addition to flux and changes of objects, these also would have happened frequent exposure to a broad general relativity of understanding the outside world. Because on the basis of attitude, obtained perceptions would be numerous for each person and so would be valid for him. Finally it could be acceptable to vote for one of perceptions by the consensus of people in one way of understanding, but it is impossible to consider other claims as false and untrue. Because there is no fault and everyone is right, but understandings' a bunch of people is better for some specific interests and it must be accepted. The final result of this approach is the proliferation of knowledge and skepticism. As every perception is real even mutual perception. Therefore no cognition can claim that it is monopoly in decoding the face of the world.

On the other hand, a part of rhetoric training was that the students were taught to prove both side of a problem with equal success. He wanted to teach his students in a way that they could praise and denounce everything, and could certainly defend such weak arguments to appear to be stronger (DK: c2, a21). And also he said in "Antilogiae": "To everything there are two opposing arguments." Address training was not limited to form and style, but it was also a discussion of the nature and essence of the object. How such trainings could not indoctrinate this belief that every truth is relative and no one has certain knowledge? Indeed, it seems to be minor and variable, not general and constant, because truth for everyone is what convinces him and it is entirely possible to convince anyone that black is white. It could be to believe in, but never to know what the judge said. (Guthrie, 1994, Vol 10, 98-99).

Socrates in (Euthydemus: 286b-c) says: "Protagoras, and even thinkers before him" believe that Contradiction is impossible, and concludes that they seem impossible for someone to say the wrong words. Aristotle says (Metaphysics, 1007b18): Those who accept the words of Protagoras must accept the idea that "It could be about a single object, the conflicting statements that simultaneously, both are true" and "You can prove anything on any subject or reject it". A little later in (1009a6), after referring to the denial of law of contradiction, he says: "Protagoras word is cognate with this idea, and either or both theories are true or both false; because if all phenomena and beliefs are right, However, everything must be right and wrong, because a lot of people are having the opposite opinion. " (Guthrie, 1994, Vol 11, 4643).

So Protagoras denies any absolute and fixed knowledge and justifies all fields of knowledge with the same base and in the discussion of recognition considers the relativity and skepticism.

In fact the citation of relativity of knowledge is a kind of skepticism; it would seem that knowledge is not absolute in this idea. Indeed, we absolutely do not perceive the truth but in proportion to their cognitive abilities and forces (sensation, imagination, memory, reasoning, etc.) know the facts. So regardless of our cognitive faculties is not clear that how and what absolutely is the truth. Truth in our opinion is what we consider it (Saneii Darreh Bidi, 2006, 343). Thus cognitive relativism follows a kind of skepticism. This kind of skepticism was not only among the sensible things of this world, but it has also spread to the gods and their existence was suspected.

As we have seen, Philosophical ideas of relativism, sensationalism and individualism throughout the history of philosophy, without any dispute, has been placed among the ideas of Protagoras and no research has been done about its accuracy and inaccuracy. But in the current era, one of the most important foundations of the human sciences is the research 
about the accuracy of expressed opinions in this area; by the research Cornford and Dr. Qavam Safari have done, they have expressed some commentary and discussions about the rejection of validity of the votes assignment from Plato to Protagoras, which we will analyze it.

What we would discuss about in the following is part of the research into the epistemic relativism. In the contemporary philosophy of west, an important part of recent versions of epistemic relativism, more or less, are renewed efforts which have usually done within the framework of the revival of Protagoras in new terms and replication to the Socrates 'bugs. Protagoras time ever, some scholars have advocated epistemic relativism. And against them, many thinkers have not accepted this theory due to the problems they posed about it. Here, first, we would present the discussion between Socrates and Protagoras (quoting Plato) in Theaetetus' dialogue about relativism. The reason for selecting the Theaetetus' dialogue is that in this conversation, the main topic of discussion is review and critique of the theories of knowledge and as if epistemic relativism assignment roots to Protagoras can be found here. After reviewing some of the conversation, some contemporary narratives to defend Protagoras will be considered.

\section{PLATO EXPOSED TO CORNFORD AND DR. QAVAM SAFARI CHARGE}

As we mentioned in the introduction, Dr. Mahdi Qavam Safari in the article, "Plato's ahistorical interpretation of humanism rule of Protagoras", and Cornford in his book, "Plato's Theory of Knowledge", believe that Plato has interpreted the "humanism" rule of Protagoras, by combining it with his so-called "secret" doctrine and the theory of Theaetetus "knowledge = perceiving" in a way that it leads to perfect and very sophisticated epistemic relativism; and then in an ahistorical effort, Plato has imposed this relativism to the Protagoras' mind. Plato and, after him, many scholars and historians of philosophy and philosophers have alternatively attributed epistemic relativism and subjectivism, or both, to Protagoras, despite dramatic differences among them.

Guthrie also believes that Plato, with respect to Protagoras, disagrees widely with his beliefs and therefore he may has interpreted his views, despite the possibility of different interpretations, in a way that those ideas seem completely irrational. This is especially true in this sense that Plato is not a historian of philosophy and even when he attempts to narrate philosophical thoughts in the time before him, his narration is clearly not quite historic; but it is a story that a philosopher, such as Plato, narrates it and so it is more writing of philosophy rather than writing the history of philosophy. This is perfectly normal and we should not expect to read the history of philosophy in the dialogues of Plato or, for example, the works of Aristotle and Hegel and even Jaspers. However the point of the matter is that contrary to the idea of Greek historian, Lesky, disagreement with some interpretations of Plato about the views and beliefs of his predecessors does not mean that we distrust him or know him as a "liar", but it only means that Offering a different interpretation of Plato's interpretation is where, there are other possible interpretations. (Guthrie, 1962, 189)

Plato attempts to review and criticize the theories of knowledge in dialogues of Theaetetus. The first theory is the theory of knowledge which is based on "knowledge is perceiving". As also mentioned earlier, according to Plato's approach of analysis, he believes that finally Theaetetus' theory of knowledge is united with Protagoras' rule of humanism and Heraclitus theory of becoming. (Plato, 1961, Theaetetus, 160e) It is as if Plato believes that Theaetetus' theory of knowledge is based on the epistemological theory of Protagoras (man is 
the measure of all things) and cognitive theory of Heraclitus (becoming popular and enduring objects).

Plato tries to draw a connection between these three theories in front of the reader; so as soon as he poses the theory of "knowledge = perceiving", he considers it as a different expression of Protagoras 'humanism rule. For relevance and connection of Theaetetus' theory of knowledge with humanism rule, he begins the subject with the example of "the same wind" and its different perceiving from those two men, and says:

\section{Socrates}

That you have given, but one which Protagoras also used to give. Only, he has said the same thing in a different way. For he says somewhere that man is "the measure of all things, of the existence of the things that are and the non-existence of the things that are not." You have read that, I suppose?

\section{Theaetetus}

Yes, I have read it often.

\section{Socrates}

Well, is not this about what he means, that individual things are for me such as they appear to me, and for you in turn such as they appear to you - you and I being "man"?

\section{Theaetetus}

Yes, that is what he says.

\section{Socrates}

It is likely that a wise man is not talking nonsense; so let us follow after him. Is it not true that sometimes, when the same wind blows, one of us feels cold, and the other does not? or one feels slightly and the other exceedingly cold?

\section{Theaetetus}

Certainly.

\section{Socrates}

Then in that case, shall we say that the wind is in itself cold or not cold or shall we accept Protagoras's saying that it is cold for him who feels cold and not for him who does not?

\section{Theaetetus}

Apparently we shall accept that.

\section{Socrates}

Then it also seems cold, or not, to each of the two? 


\section{Theaetetus}

Yes.

\section{Socrates}

But "seems" denotes "perceiving"?

\section{Theaetetus}

So the hot and cold and in cases such as those, "appearing" is as "perceiving". Those individual things are for anyone such as those appear to them; or assume that they are such a thing. (Ibid, 152c-151e)

As Qavam Safari says, the main source of attributing Relativism to Protagoras is this section of the dialogue of Theaetetus which here, of course, was posed with some removed parts. In his point of view, for many readers throughout the history, Plato's eloquent writing and powerful expression causes to be agree with his reasoning with no doubt, as Theaetetus does. Although Plato has wrote this part of dialogue to clarify the meaning of the doctrine "knowledge = perceiving" and thus, "Humanism", but his own writing is not less ambiguous than Protagoras' words. He also has attributed some subjects to Protagoras as he interprets his words that we believe, besides not coordinating together, these are made by Plato, himself. He also believes that Plato could have incorporate the doctrine of Protagoras with another doctrine of Heraclitus and also Anaxagoras, to conclude that it is not easy to attribute Subjectivism and even Relativism to him. Some specialists in Greek philosophy have also believed that Plato's result is that much real that they simultaneously have attributed both Relativism and Subjectivism to Protagoras. For example Guthrie believes that:

The best title to describe Protagoras' standpoint is "radical subjectivism", because this title includes perceiving as well as thoughts and beliefs, unlike the title, "positivism" and "phenomenalism", and equally applied on sensible matters such as hot and cold, and also the concepts of true and false. In Guthrie's opinion, according to Protagoras' radical subjectivism, "there is no reality beyond phenomena and unrelated to them; there is no difference between appearance and existence" (Guthrie, 1969, 186). Therefore, Qavam Safari considers ambiguity and even amphibology in some parts of Plato's writing about Theaetetus, and believes that his results in this section are not acceptable without scrutiny.

According to these two cases, Cornford accuses Plato for his untrue, ahistorical interpretation of the theory of Protagoras, in the analysis of this part of Plato's dialogue in the book "Plato's theory of knowledge": firstly, based on the text of Theaetetus dissertation; and secondly, based on the report of Sextus Empyricus.

A - Analysis and review of Cornford's opinion, based on the text of Theaetetus' dialogue: He translates a part of the item $152 \mathrm{~b}$ which is already the main sightly subject:

"Socrates: Then in that case, shall we say that the wind is in itself cold or not cold or shall we accept Protagoras's saying that it is cold for him who feels cold and not for him who does not?" (Cornford, 1960, 32)

In fact this statement is a conditional theorem of the kind of detached. In other words, Socrates and Theaetetus are encountered with dilemma to choice between two different rules; which at least do not have possibility to make consensus. Cornford has no comment about the provisions of primary theorem (shall we say that the wind is in itself cold or not cold?) and 
also this point that the whole phrase is a detached. His discussion about the provisions of secondary theorem or second part of the statement reveals Protagoras' idea. He believes that the statement, "or shall we accept Protagoras's saying that it is cold for him who feels cold and not for him who does not" includes a variety of interpretations and among them are two possible interpretations which are:

1. "the wind is in itself cold or not cold". Heat and cold are two features which have the possibility of co-exist in a unit of a natural object. I feel one of that features and you, another.

2. "the wind is in itself not cold neither not cold". Wind has none of the features which we feel them separately and with sense, and the wind itself is not understandable with sense. Wind is something out of us and makes us to feel cold and warmth. Our sensory belongings, such as cold and warmth besides natural objects spread out independently, do not exist. But only when the action of perceiving is occurred, sensory belongings of cold and warmth are happened.

According to Cornford, between these two theories, it's more likely that Protagoras claims the first and simplest interpretation: it's based on that the wind is cold and also not cold. The second theory and interpretation (the wind is in itself not cold neither not cold) is a main characteristic and feature of the theory of perceiving which is promptly suggested as a "secret training". The feature of this interpretation is that this named training is not found in Protagoras' book. The first theory has not left the treatment of Naïve Realism to common praxis; the same attitude and mentality which does not hesitate that features to perceived sense by us do not exist in objects themselves". (Ibid, 33-34)

For best result, we bring the reading of Cornford with the second reading of the text together to easily discover similarities and differences between them:

- Cornford's reading of the text: "shall we say that "the wind is in itself cold or not cold" or shall we accept Protagoras's saying that "it is in itself nor cold neither not cold" ".

- Second reading of the text: "shall we say that "the wind is in itself cold or not cold" or shall we accept Protagoras's saying that " it is in itself cold and also not cold" ".

As we see there is only one difference between the two readings:

The secondary theorem in Cornford's reading superintends on the general sentence, "refusal of the unity of opposites". Cornford has no rational and justified reason for his interpretation, but another one has become justified and reasonable according to logic criteria and considering two terms: loyalty to discontinuity (dilemma facing Socrates and Theaetetus); and adherence to primary provisions in the words of Plato's text. So by the existence of logic reasoning in the review of Cornford's reading the text of Theaetetus' dialogue revealed that Cornford's reading is nor loyal to primary theorem, available in content of the item $152 \mathrm{~b}$, neither compatible with detached mode (separate or paradox) means dilemma in front of Theaetetus. But the second reading contains both case and is in front of Cornford's reading from this perspective. So, Cornford's reading does not coordinate with items 158e-159e from Theaetetus' dialogue.

Earlier we saw that Cornford claimed: it is likely that Protagoras asserts the first and simpler interpretation among two theories, based on that wind is warm and cold together. The second interpretation is a main characteristic and feature of the theory of perceiving which 
would immediately be suggested as a "secret training". This interpretation requires that named training could not be found in Protagoras' book." (Ibid, 35).

As Cornford says, Plato ascribes the expression "refusal of the unity of opposites", which according to the theory of perceiving means only interacting active objects with passive senses, to Protagoras. But Cornford's elicitation is contrary to the explicit text of Theaetetus' dialogue; since Plato, according to secret training of perceiving in the items $158 \mathrm{e}$ to $159 \mathrm{e}$, presents explanation of the theory of perceiving by using the analogy of "healthy Socrates and ill Socrates" and tasting wine. By this presentation, Plato talks explicitly of the theory of historical Protagoras about opposites co-exist on the unit of wine itself and the advent of each of the two on the senses of healthy and sick Socrates.

Therefore, by ignoring the conflict of his reading with the named items, Cornford has committed the mistake and represented a distorted face of Plato.

But the question that arises in this regard is whether these words are Plato's own description or the quote of Protagoras' own words?

As we saw, Cornford was willing to consider Theaetetus' interpretation justly as a quote, and this idea of his led to contradiction between his own interpretation with the original text.

Guthrie also says that "it should be a part of Protagoras' own reasoning". (Guthrie, 1969, 171).

But Dr. Qavam Safari believes that it cannot be a quote, because firstly Plato's own interpretation in Theaetetus prior to that, is "and he meant something about..."; and then to discussed explanation, Socrates immediately asks Theaetetus, "Does he mean that?". This interpretation is also repeated in Cratylus and it is clear that if it was a quote, it was inapposite to represent this statement. Secondly, in 152a 4, Socrates tells Theaetetus: you have read Protagoras' words without any doubt, and he answers: I have read it "often". So if those words were quoted, Socrates did not need to ask Theaetetus that "Does he mean this?" after explaining the "purpose" of Protagoras. Thirdly, if that explanation, in fact, was quoted, it was clear that "man" in the rule of "humanism" refers to the human individuals and any person has been in consideration of Protagoras. So those who consider it as the quote, should never talk about it that whether the man used in Protagoras' rule is partial man or total man?, or perhaps he was not aware of differences between them.

Thus according to him, there is no evidence that we consider those interpretations as the quote and even the style of Plato's literature allows us to consider those words as Protagoras' own words. So his word is inevitably limited to the rule of "humanism" and remains in its ambiguity. We should consider these explanations as Plato's interpretation of Protagoras' words that if it was so we would get an important result: it is possible to present another interpretation instead of Plato's interpretation of Protagoras' words and his interpretation is not the only possible interpretation. This result could be effective in the way of understanding Protagoras' words, because as we saw, we could understand his word in another way.

B - Analysis and Review of Cornford's opinion on the basis of Sextus Empyricus' report:

Sextus Empyricus, Greek philosopher and skeptic of third century AD, in a book named "Pyrrhonic Sketeches" talks about the theory of Protagoras. Cornford, in book "Plato's theory of knowledge", quotes an important issue from Sextus which we bring it exactly here:

"Protagoras says that objects consist of basic fields of all manifestations and appearances. Therefore object is an independent issue and could be all things which appear to all humans.Humans perceive various objects according to changes in their circumstances and conditions in different times. A person in the normal situation perceives the things of an 
object which are possible to appear for a usual man; and a person in the abnormal situation perceives the things of an object which are possible to appear for an unusual man. This rule is true on different times and days of life, on sleep-wake states and on any condition. Thus, according to Protagoras, it is confirmed that human is the criteria of what exists: whatever appears to man is in a way that exists and anything that does not appear to anyone, does not exist". (Cornford, 1960, 35, quoted from the paper " Pyrrhonic Sketeches " By Sextus).

According to this report, some of the main elements in the thought of Protagoras are:

1 - The existence of any matter or thing which contains the basic fields all manifestations and expressions which appear to humans.

2 - Ability to "emerge" status and qualities of external objects on the senses of men, in any case, (the issue of the representation of the senses); either normal (i.e. healthy) or abnormal conditions (such as illness).

3 - Variation in the appearance and manifestations of what appear is subject to some factors such as senses states, multiplicity and objects change and time difference (The importance of the interaction between foreign affairs with senses).

4 - Understanding the being or not being of a thing and how to be and how not to be, depends on appearance or non-appearance of that thing on human senses. As a result, human is the criteria of being and not being of affairs.

5 - Existence of the principle of causality and admission of relating senses with reality in cooperation with external objects is also among the basic assumptions of Protagoras.

Cornford believes that the historical Protagoras, like Heraclitus and Anaxagoras, respects to the theory of "co-exist and unity of opposites", while Plato introduces Protagoras as someone who is the contender of the theory of "refusal of the unity of opposites". (Ibid, 33-34).

According to the mentioned issues, there is no conflict between what achieves by the report of Sextus, with Plato's interpretation of Protagoras' thought. According to the report of Sextus Empyricus as an impartial source, text of the item $152 \mathrm{~b}$ verifies the introduction of true Protagoras by Plato. Sextus' report contradicts Cornford's self-made Plato. Indeed, the problem of this issue is concerned with Cornford's inaccurate reading of the expression of the item 152b in Theaetetus' dissertation, which during that reading, Plato is introduced as one who considers Protagoras as the pursuant of the theory of "refusal of the unity of the opposites"; while this immature and unreflective treatment is by Cornford himself. Cornford represents a face for Plato as the garbler of Protagoras' theory and then he arises against him and accused him of making a false interpretation of Protagoras.

But Dr. Qavam Safari responses to this criticism in this way that: assuming these statements are Protagoras' purpose, can we consider him as the relativistic only because of this idea, or not? Then he analyzes this subject:

In his view, after quoting these words of Sextus, Cornford adds properly that "If this is Protagoras's view, his doctrine would not be subjectivism; even the term "relativism" is also dangerously misleading". (Ibid, 35). In accordance with Sextus' interpretation, objects, means traits and characteristics, exist, whether anyone will understand them or not. Therefore Cornford correctly concluded: "The result is that the second view which says: As long as a person does not understand the wind It is neither cold nor hot, is the interpretation that Plato believes in, due to vague words of Protagoras." (Ibid, 36). In other words, the view is an interpretation which Plato attains by flux "secret training". 
In the following, Qavam Safari noted to Guthrie's opinion as opposed to this interpretation. Guthrie believes that Cornford has quoted Sextus' words incompletely because Sextus, in the sentence before the quoted items, ascribes the doctrine "object is in flux" to Protagoras. He writes in the following: "This definitely belongs to "secret training", and when Sextus tries to go beyond the theory of "humanism" and its explicit essentials, it discredits his testimony on Protagoras' noble thoughts. (Guthrie, 1969, 185).

But from his point of view, three points need to be noted about Guthrie's words. First, Cornford is not unaware of Guthrie's sightly sentence which Sextus ascribes it to Protagoras, and even shortly after the discussed item, he quotes and interprets it: "In fact Sextus says that Protagoras believed "Object is in flux" and during its flux, additives compensate for excreta, and our feelings are modified according to the different times of life and physical condition. Those words may just mean that additives compensate for feeding of fixed excreta. (Cornford, 1960, 35).

It should also be noted that he documents his words about nourishment and compensating the excreta by party d207 and fidon d87, and adds that Sextus' source is unknown in attributing flux doctrine to Protagoras and probably he has also involved in misunderstanding due to Socrates' report by which he introduces Protagoras as the follower of flux doctrine.

Second, we assume that Sextus would have an independent source except Plato himself in Theaetetus by attributing flux doctrine to Protagoras. On the basis of this assumption, unlike Guthrie's conclusion, we attain this result which only according to flux doctrine and contrary to Plato's interpretation, does not lead to interpret his words about the theory of humanism to epistemic relativism or even worse "radical subjectivism": it means that we could consider him as a believer in flux doctrine, but two results of epistemic relativism and radical subjectivism could be ignored of attributing to him.

Third, if presenting secret training of flux, according to Guthrie, leads to go beyond the humanism and its explicit essentials and therefore discrediting the testimony of a person about Protagoras' main thoughts, it is astonishing that why Guthrie ignores this point about Plato and does not say that he is the first person who goes beyond his "humanism" and "its explicit essentials" by presenting flux doctrine as secret training, and attributing it to Protagoras. Thus "he discredits his testimony about Protagoras' noble thoughts".

So Dr. Qavam Safari has associated with Cornford rejecting this criticism and insisted in his claim based on Plato's accusation about attributing epistemic relativism to Protagoras. He also presents other reasons except from Cornford's reason to prove this accusation. Here are a few examples of these reasons which we would mention them briefly:

In his opinion, if we even consider the meaning of the word, faintai, as "sensorial sounding", the time of declaration of rule, with regard to historical context is not acceptable. Plato's equation, among the sensory data, is acceptable only when, firstly we consider difference between the substance and its qualities, and secondly we do not accept the possibility of comorbidity of antithetic qualities in unity of substance. These are two conditions of "faintai = sensorial sounding", interpreting Protagoras' rule to epistemic relativism requires them to fulfill; but unlike procedure of the history of the development of concepts, attributing a clear understanding of those two conditions to Protagoras, and also attributing the condition "faintai = sensorial sounding" to he, surely are untrue interpretations in the absence of insight evidences. So no one can judge about the beliefs of others while has no clear conception of their existence or absence, based on certain concepts, let alone that attributes logical implications of limited and distinctive meaning of that concept to them. This is while Plato not only attributes a specific meaning of the word, faintai, to Protagoras, but 
also in criticism to his rule, Plato does not remain faithful to the meaning of the word which he has attributed to Protagoras.

His reason for this disloyalty is that Plato goes beyond the semantic field of "sensorial sounding" when criticize the rule, not just in terms of word, but due to the meaning and conception. He expresses that he has legal concept of "sounding" in his mind: If the Protagoras' truth is really true, and whoever would be the only criterion for his own vote and beliefs arbitration, thus Protagoras does not have any right to know himself superior to others and teach them. This is while we have to assume ourselves not as wise as him, and should participate in his teaching class. If Protagoras' rule is not a joke, then "total occupation to dialectic" (161e 6) would be an "amazing and dull performance of stupidity" (162a 1).

On the other hand, we also remember that when Socrates wanted to make clear Protagoras' purpose, he exemplifies the wind. He said that it is possible to consider the same wind as cold in one's opinion, and warm in another's opinion. Now passing this example which absolutely induces the sensorial concept of faintai to "total occupation to dialectic" and surely inducts legal concept of faintai, or in other words, the meaning of dokei, is the important extended sign and Plato's intellectual incoherence in narrating and criticizing humanism. Now we believe, as Jonathans Barnes says, that "So Plato is not faithful consistently phenomenological interpretation, offered in Theaetetus 152 a". (Barnes, 1989, 543)

Qavam Safari investigates this disloyalty from another aspect. In this opinion, due to example of the wind, being the human thought as the criteria is only limited to a predicate. The wind blows, one feels it cold, another feels not cold. The first one says: the wind is cold, while the second one says: it is not cold. The wind here is a unit affair which we speak about its kind of description. If we just consider what has mentioned till now, we should definitely present Protagoras' rule, contrary to the opinions of some commentators:

"Man is the measure of all things,

The criterion is the modality of things which exist, and

The criterion is the lack of modality of things which do not exist.

That is, if I feel the wind is cold so I am the criterion of being cold for the wind, and if I feel that the wind is not cold, so I am the criterion of being not cold for the wind. So the rule with this presentation is only observing the predicate existence and we only expect this matter and nothing else. Aristotle, as well as Barnes, has pointed out that (ibid, 544) he would accept Plato's predicate interpretation which comes from example of the wind. While he discusses about the result of Protagoras' words, he also states that carting of opposites is impossible simultaneously in one substance. But if Protagoras' words be accepted, it would lead to this impossible result that carting of two opposites become possible: "If anyone thinks that man is not a battleship, so he's not a battleship, but..."(Aristotle, Metaphysics Gamma 4, 1007 b 23). Thus Plato, by exemplifying the wind, limits being human thought as measure merely to predicate existence, and it is not compatible with phenomenological interpretation presented in Theaetetus.

So Dr. Qavam Safari, by using the meaning of "faintai = sensorial sounding" and also Plato's disloyalty to doctrines stated in his dialogue, shown that Plato's interpretation of Protagoras' humanism cannot be a historical interpretation. He, besides Cornford and by mentioning some recalled reason, accused Plato for forging ahistorical Protagoras. He believes that Plato has imposed some certain ahistorical subjects to Protagoras' mind. They also believe that Plato, by relating humanism to his own favorite doctrine which calls it as 
secret doctrine of Protagoras and also by harmonizing that rule and that doctrine with the theory of Theaetetus "knowledge = perceiving", successes to represent that interpretation and gradually distributes it from traits to essence, and establish the most advanced form of epistemic relativism. So, as these two commentators believe, historical Protagoras is different from Protagoras who Plato has introduced.

\section{CONCLUSION}

As we saw, some different critiques and interpretations are represented by great thinkers of the world of philosophy on Plato's dialogue and his critique toward Protagoras. None of these critiques has seriously proved Plato's accusation in attributing of untrue ideas to Protagoras. There is still need for debate and responding to these critiques. But what is hopeful, is opening new gates of these critiques and interpretations which cause to further and more exact reading of Plato's dialogue in order to achieve new philosophical points in these dialogues.

\section{References}

[1] Aristotle, Metaphysics, translated by Mohammad Hassan Lotfi, Tarh-e-nov Publication, Tehran, (2006).

[2] Barnes, Johnathan, The Presocratic Philosophers, Routledge, London, (1989).

[3] Copleston, Frederick, Volume 1, History of Greek and Roman philosophy, Translated by Seyyed Jalal al-Din Mojtabavi, Edition 4, Tehran: Cultural and Scientific Publishing Co and Soroush Press, (2001).

[4] Cornford, F. M., Plato's Theory of Knowledge, fifth impression, Routledge \& Kegan Paul, London, (1960).

[5] Diels, H. and Kranz, Ancilla to the Pre-Socratic Philosophers, A complete translation of the Fragments in Diels Fragment der Vorsokratiker by: Kathleen Freeman, Cambrifge, Massachusetts: Harvrd University press, (1948).

[6] Durant, William James, History of Civilization, Volume 2, A group of translators, Tehran: Teaching Islamic Revolution, (1991).

[7] Foroughi, M. A, Development of Philosophy in Europe, Alborz Publication, Tehran, (1996).

[8] Guthrie, W. K.C, History of Greek Philosophy, Vol 2: Anaximander \& Anoximenes, Translated by Hassan Fathy, Fekr-e-rouz publications, (1996).

[9] Guthrie, W. K.C, History of Greek Philosophy, Vol 10: Sophists (Part One), Translated by Hassan Fathy, Fekr-e-rouz publications, (1996).

[10] Guthrie, W. K.C, History of Greek Philosophy, Vol 11: Sophists (Part Two), Translated by Hassan Fathy, Fekr-e-rouz publications, (1996).

[11] Guthrie, W. K. C, A History of Greek Philosophy, Volume One, Cambridge University Press, London, (1962). 
[12] Guthrie, W. K. C, A History of Greek Philosophy, Volume Three, Cambridge University Press, London, (1969).

[13] Holling, Dale, R. J, Principles and History of Western Philosophy, Translated by Abdal-Hossain Azarang, Keyhan Publication, Tehran, (1997).

[14] Jaeger, Werner, Paideia, Translated by Mohammad Hassan Lotfi, Volume 1, Khwarizmi Publishing Company, Tehran, (1997).

[15] Jaeger, Werner, Paideia, Translated by Mohammad Hassan Lotfi, Volume 2, Khwarizmi Publishing Company, Tehran, (1997).

[16] Kerferd G.B., The Sophists. Routledge History of Philosophy 1 (1997) 225-245.

[17] Mahdavi, Y, Skeptics of Greece, Khwarizmi Publication, Tehran, (1997).

[18] McDowell, John, Plato, Theaetetus, Translated with notes, Seventh impression, Oxford, (1991).

[19] Motahari, M., Philosophy and Realism, volume 1, Sadra, Tehran, (1993).

[20] Plato, Protagoras, Translated with Notes by C.C.W. Taylor, fell of corpus Christi College Oxford University Press, (2002).

[21] Plato, Period of Plato's work, Volume 1, translated by Mohammad Hassan Lotfi, Third edition, Tehran: Khwarizmi Publishing Company, (2001).

[22] Plato, Period of Plato's work, Volume 2, translated by Mohammad Hassan Lotfi, Third edition, Tehran: Khwarizmi Publishing Company, (2001).

[23] Plato, Period of Plato's work, Volume 3, translated by Mohammad Hassan Lotfi, Third edition, Tehran: Khwarizmi Publishing Company, (2001).

[24] Plato, Period of Plato's work, Volume 4, translated by Mohammad Hassan Lotfi, Third edition, Tehran: Khwarizmi Publishing Compan, (2001).

[25] Qavam Safari M., "Plato's Ahistorical interpretation of Protagoras' Theory of Humanism ", Zehn Journal 10 (2002) 56-27.

[26] Saneii Darreh Bidi, M., Foundations of Philosophical Thought (General Philosophy), Tehran: Amir Kabir institute press, (2005).

[27] Takrini, Najy, Platonic moral philosophy, First Edition, Baghdad: Andalusia, (1979 $\mathrm{AD})$.

[28] Theodor, Gomperz, Greek thinkers, Volume 1, Translated by Mohammad Lotfi, Tehran: Khwarizmi Publishing Company, (1996). 